\title{
Demographic determinants of mobile marketing technology adoption by small and medium enterprises (SMEs) in Ekiti State, Nigeria
}

\author{
Sunday C. Eze ${ }^{1 凶}$, Hart O. Awa ${ }^{2}$, Vera C. A. Chinedu-Eze ${ }^{3} \&$ Adenike O. Bello ${ }^{4}$
}

\begin{abstract}
A substantial number of factors have been examined on the potentials of SMEs to exploit mobile marketing devices to achieve a competitive edge. However, the limited scholarly investigation has focused on the demographic characteristics of top executives of SMEs and how the location moderates the interaction between the demographic structure of SMEs' executives and the rate of mobile marketing technology adoption, particularly in the southwest of Nigeria where adoption of these devices are slow. The research examines the effects of demographic factors of top SME executives on mobile marketing technology adoption in Ekiti State Nigeria. Data were collected through questionnaires and responses of 230 SMEs were drawn randomly from a population of 620 registered SMEs operating in 6 different industries located in different towns in Ekiti State, South-West Geo-Political Zone, Nigeria. Hierarchical multiple regression was used to analyse the data. Results revealed that the experience, age, and educational attainment of top SMEs' executives were statistically significant, and the location of the firm significantly moderated mobile marketing technology adoption. Gender also affected mobile marketing technology adoption among SMEs.
\end{abstract}

\footnotetext{
${ }^{1}$ Department of Business Studies, Landmark University, Omu-Aran, Nigeria. ${ }^{2}$ Department of Marketing, University of Port-Harcourt, Port Harcourt, Nigeria. ${ }^{3}$ Department of Agri-Business and Management, Michael Okpara University of Agriculture, Umudike, Nigeria. ${ }^{4}$ Department of Business Studies, Landmark

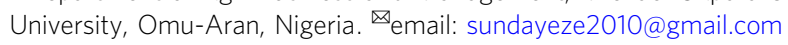




\section{Introduction}

lthough multinational organisations and the government play a leading role in the economy, SMEs are the drivers of the socio, national, economic growth (Mutuala and Brakel, 2006; Shareef et al., 2017; Eze et al., 2019a; Apulu et al., 2011), employment generation and innovation (Scupola, 2009; Eze and Chinedu-Eze, 2019). Small businesses represent over 96 per cent of businesses in most Organisation for Economic Cooperation and Development (OCED) countries (Eze et al., 2014; Tong et al., 2020) and account for over 79 per cent of the economic growth (Eze et al., 2014). The definition of SMEs differs between countries, regions and industries which draws on factors such as the total number of the workforce, capital invested, yearly income, nature of the business or a blend of all these factors (Gamage, 2003; Apulu et al., 2011; Eze et al., 2019b). In European countries, for example, SMEs employ between 400 and 500 workers (OECD, 2000a, 2000b); while in Australia SMEs employ between 150-200 workers and between 100 and 200 workers in South Africa (Scupola, 2009). However, the European Union categorised SMEs into three: (i) micro-enterprises which consist of business with less than ten employees (ii) small enterprises are businesses with 10-49 employees and (iii) medium enterprises that employ 50-199 workers. In order to improve small business' strategic position, competitiveness, and their success within regional and international markets, mobile marketing devices are essential for collaborative businesses. The advances in the internet have made the world a global village and mobile marketing technologies offer SMEs the prospects of strengthening competitive advantage against large organisations (Eze et al., 2019b; Scuola, 2009; Castelo and Thalmann, 2019).

Studies on innovation adoption (Thong, 1999; Rogers, 1995; Tornatzky and Fleischer, 1990) promote individual difference factors (IDFs) because each organisation differs in structure, operation, decision-making styles, cognitive insight and assumptions about alternatives and consequences of the future. Several studies (Eze and Chinedu-Eze, 2018; Thong, 1999; Investopedia, 2018; Awa et al., 2010; Castelo and Thalmann, 2019) viewed individual innovativeness as the ability and willingness to novelty, and organisations direction is associated with the values, intellectual base of the people and the distinctiveness of the minds (Chaung et al., 2009; Shiau et al., 2009; Investopedia, 2018). Hence, there is an association between the background of the executive activities, length of service in an organisation and unwillingness to expand. Eze et al., 2019b stressed that the decisions of SMEs are often left in the hands of the owner, who with few other family members exploit and strategically reposition the future direction of the business.

According to Albaladejo-Pina, and Díaz-Delfa, (2009) urban cities are more attractive for business opportunities compared to rural areas, and there are different values for related enterprises, and related values for diverse enterprises. Mobile marketing platforms tend to bridge the barriers of geographical location although agglomeration economies are still evident in Nigeria. The fact is that the rate of development varies and is unequally distributed across many areas, and adoption opportunities may differ despite the fact that Nigeria's ICT adoption is still growing (Awa et al., 2015). The growth may not be sustainable because of the narrow focus on the upper and middle classes. Uzor (2013) revealed that aside from these upper and middle classes of people living in some cities and regions, a number of these low-income earners give on-line businesses a boost in Nigeria. Extensive literature review revealed that studies on the demographic determinant of top SMEs' executives on technology adoption have advanced over the years, and some of these researchers (Uzor, 2013; Awa et al., 2015) have argued that the location of the firm is one of the elements of technology adoption drivers. However, how such location moderates the interaction between the demographic composition of SMEs executives and the rate of mobile marketing adoption is understudied (Awa et al., 2015; Castelo and Thalmann, 2019). Little attempt has been made to investigate if the difference in the demographic composition of top SMEs executives and the rate of mobile marketing technology adoption may be explained by the changes in the geographical location of the firm (Awa et al., 2015; Tong et al., 2020). However, indigenous scholarship offers directions and guidance to this kind of investigation, especially in Ado Ekiti, South-West, Nigeria. Owning to the vital role SMEs play in the economic development of Nigeria, and the limited frameworks that may serve as a guide for SMEs in Nigeria necessitated the study.

Therefore, the purpose of this study is to investigate the influence of gender, age, experience and education of top SME executives on the adoption of mobile marketing technology infrastructures in a south-west geopolitical zone of Nigeria. This is an attempt to bridge the gap by developing a framework that measures location as a contextual variable between mobile marketing technology adoption and the demographic composition of top SMEs executives.

\section{Review of related literature}

Small and medium enterprises in Nigeria and mobile marketing technology adoption. According to the Central Bank of Nigeria (CBN), an SME is a company that employs from 11 to 100 people and has assets between $\$ 5$ million and \$500 million. Small and medium enterprises are becoming increasingly important for the creation and development of a modern, dynamic and knowledge-based economy (Ongori and Migrio, 2010). This is because of their capacity to promote entrepreneurship and entrepreneurial skills, and because of their ability to be flexible and adapt quickly to a changing market, and to generate new jobs (Shareef et al., 2017). The development of small and medium scale enterprises is vital to the growth of the national economy. Small and Medium Enterprises are considered to be a major employment source for the nation and to contribute significantly to the country's productivity and job creation and the overall national domestic product. Despite all these potentials, the SME sector in Nigeria has failed to fully incorporate mobile marketing technology into its mainstream operational setup (Eze et al., 2019c). The Nigerian government has invested many resources to promote the sector for national economic growth. For instance, the government of Nigerian established some agencies like the Central Bank of Nigeria (CBN) and microfinance banks and Small and Medium Enterprises Agency of Nigeria (SMEAN) to improve the creativity, competitive edge and innovative models to assist SMEs (Ojeme and Onuba, 2010). The CBN, for example, sets up SME credit guarantee scheme worth over N190 billion to stimulate manufacturing, service, and agricultural value chain, packaging and distribution of certain primary products (Ojeme and Onuba, 2010). However, SMEs are still challenged with certain obstacles in adopting mobile technology and thus, sceptical in implementing these applications (Shareef et al., 2017). The majority of decisions made about mobile technology adoption are often left for the manager to make decisions that will affect the business with their family members.

Small and Medium Enterprises in Nigeria often believe that advances in mobile platforms will transform and boost their business accomplishments but when compared with what is happening in the western world Nigerians seems to be engaging in a derivative approach (let us see how it will turn out) in adopting mobile or electronic platforms. The beauty of mobile 
platforms is the ability to provide innovative worldwide infrastructures (Al-Qirim, 2007) that integrate business associates and services (Ongori and Migrio, 2010). This improves and promotes sufficient flow of information and work flexibility (Ongori and Migrio, 2010). Therefore, mobile platforms offer a new approach to communications, business relations, market structures and new ways to teach (Eze et al., 2019a).

The term "mobile" is fast evolving from just being described as a phone to encompass different sets of portable computing devices and mobile services (Tong et al., 2020). Mobile marketing technology has transformed the manner in which small businesses operate and relate with customers. This alone has created new business opportunities (Investopedia, 2018) for SMEs. Although the definition of mobile marketing technology differs Balasubramanian et al. (2002) defined mobile marketing as a way through which two or more persons (e.g., a firm and its customers) interact and promote an offer using a mobile device, technology, or application. As mobile marketing technology continues to gain momentum, SMEs use these devices to communicate, obtain vital business information, initiate and interact with customers. Mobile technology is considered an asset that helps the coexistence of a firm, its stakeholders and partners (Castelo and Thalmann, 2019). These definitions suggest that businesses can use these platforms in real-time to relate (Eze et al., 2020; Ciechanowski et al., 2019). It involves communication through mobile devices, mobile trading, mobile data interchange (MDI), mobile money transfer (MMT), mobile mail (m-mail), mobile catalogue, mobile directories (Eze et al., 2019b; De Haan et al., 2018). These platforms help small businesses to develop business ideas and business partnerships that will enhance the value-chain through inter and intra-organisation information sharing that builds collaborative environments (Raymond and Bergeron, 2008; Dubé et al., 2017). These, most times lead to the development of advanced levels of product and process innovation which enhance competitiveness and reduction in cost as a result of disintermediation, inventory holding, virtual stores, and transparency in improving customer service (Yesbank, 2009; Fong et al., 2015; Economides and Jeziorski, 2017; Ciechanowski et al., 2019; Kannabiran and Dharmalingam, 2012; Alba et al., 2005; Economides and Jeziorski, 2017). Hence, small businesses may have the capacity to exploit opportunities associated with mobile marketing technologies compared to large organisations, considering their limited human and financial resources and mode of operations which support fast decision making.

With the nature of mobile technology, small businesses are likely to adopt mobile marketing, systematise processes and reach out to clients without having to pass through intermediaries and engage in active communications networks. Shankar et al. (2010) observe that mobile technology can aid small businesses to increase productivity, control inventory, boost sales and aid in the delivery of products faster. However, some studies found that the rate at which SMEs adopt and utilise mobile marketing technology is relatively low and slow in many countries compared to large establishments (Hadidan 2020; Balasubramanian et al. 2002; Shankar et al., 2010; Kannabiran and Dharmalingam, 2012). Hadidan (2020) noted that the high rate of penetration of mobile technology in large organisations is because large businesses are strong financially and have technical experts that can identify alternative mobile marketing platforms that will support their business activities and meet their operational requirements.

Small and Medium Enterprises are flexible and open to innovation, although they still lag in developing and adopting new solutions to the fullest. However, mobile marketing technology adoption has risen globally with an annual rate of $24 \%$ between 2000 to 2008, which saw adoption rising above 3.9 billion in 2008 (Shankar et al., 2010). A more recent finding shows that half of the customers in the United States are mobile users (Ghose et al., 2019). In the UK, a study shows that $71 \%$ of consumers have increased their spending through mobile devices (Park and SuJin, 2006). Furthermore, a study revealed that $90 \%$ of organisations were at the forefront of initiating and adopting mobile marketing technology and almost two-thirds of these organisations devote $25 \%$ of their total marketing expenditure to mobile marketing devices (Sultan et al., 2009). These suggest that organisations are even spending more on acquiring and adapting to mobile marketing applications. The fact that a large number of businesses are involved in the implementation of mobile marketing today suggests that mobile marketing devices have come to stay as a strategic tool for most businesses (Shankar et al. 2010; De Haan et al., 2018; Charoensukmongkol and Sasatanum, 2017). However, most small businesses only use such platforms to send mails and acquire information (De Haan et al., 2018). There is limited research evidence that supports that small businesses devote their resources to adopting mobile devices since 15 to 30 SMEs engage the services of IT practitioners or have ICT departments.

However, various research work (Ma et al., 2009; Shankar et al., 2010; Windrum and Berranger, 2002; Mehrtens et al., 2001; Ghose et al., 2019) in different economics have identified some peculiarities concerning challenges and benefits, inhibitors and enablers of mobile marketing technology adoption. Simpson and Docherty (2004) identified adoption drivers in the UK as being associated with low cost, organisation control, and external pressures while barriers include the dearth of awareness, absence of strategic direction, and inadequate resources. Lucchetti and Sterlacchini (2001) conducted their study in Italy. They found that inadequate finance, lack of technical know-how and security issues constituted barriers to mobile marketing technology adoption.

In contrast, MacGregor and Vrazalic (2005) found that lack of know-how, poor IT knowledge; poor awareness and cost of executing mobile solutions inhibit its adoption. In Nigeria, Apulu et al. (2011) identified competitive advantage, time-saving and cost reduction as critical drivers of mobile marketing technology adoption. Others include perceived benefits, size of the organisation, the pressure outside the organisation, locations, cost reduction; the complex nature of the application and service providers (Brown and Lockett, 2004; Gill et al., 2017; Grewal and Stephen, 2019) constitutes critical factors. Although these drivers and inhibitors mentioned shape mobile marketing technology adoption some other adoption predictors that complement these factors include management supports; managers' knowledge, managerial productivity; managers' belief differences (Grewal et al., 2017; Grewal et al., 2018).

Eze et al. (2019a) noted that mobile marketing technology adoption is dependent on the functional and emotional feelings of those that make decisions. This exposes their attitudes, perceptions and motivation. According to Awa et al. (2011), managers' or owners' participation are vital for establishing suitable mobile technology goals, identifying vital information needed and allocating resources for it (Somuyiwa and Adewoye, 2010). Caldeira and Ward (2002) investigated small businesses in the manufacturing industry in Portugal and found that top executives and their attitudes to technology adoption differ in terms of their success stories. They suggested that small businesses should build competencies from a top management perspective. Also, top management perspectives and approaches towards technology adoption are influenced by certain demographic factors such as experience, age, education and gender, among others. Extensive literature review revealed that studies on the demographic determinant of top SMEs' executives on technology adoption have advanced over the years but some of these researchers have argued that the location of the firm is one of the determinants of technology adoption drivers. However, little attempt has been made 
to investigate if the difference in the demographic composition of top SMEs' executives and the rate of mobile marketing technology adoption may be explained by the changes in the geographical location of the firm in Nigeria (Awa et al., 2015).

Mobile marketing technology trend in Africa. Mobile marketing technology is one of the core marketing strategies that have emerged in Africa in the 21st century. Its impacts have transformed both the people, organisations, societies and relationships. It is difficult for people in the western world to anticipate the impact of mobile marketing technology in Africa. Swanepoel (2015) noted that mobile marketing technology will become a first-class advertising channel that offers advertisers the opportunity to interface with the customer and promote businesses. These devices are set to gain market share in Africa from the conventional media channels to becoming the leading mass media channel for Africa. According to Swanepoel (2015), in Africa, more people have access to a cell phone network accounted for (93\%) compared to those that use electricity (64\%), pipe-borne water $(59 \%)$, or a police station (38\%), and Africa's gross domestic product (GDP) is expected to grow at an estimated rate of $50 \%$ (US\$3.7 trillion) in the next few years, based on the continuous expansion of the middle class that assists in driving the rates of urbanisation and the increase in demand for goods and services by the consumers (Swanepoel, 2015).

South Africa, for instance, has an estimated population size of 49.99 million people, $85.53 \%$ of the population is connected to a mobile network (Donga et al., 2018). Kenya and Nigeria are leading mobile payment technology. Nigeria has 97.5 million unique subscribers, $49 \%$ mobile penetration, 151 million connected to the internet, and 53 million smartphone adopters (GSMA, 2018). Thus, the growth and expansion of Africa's economy increase the mobile subscription penetration growth from 72 to $97 \%$ as Africa had millions of new smartphone subscribers (Swanepoel, 2015) and a 4.1\% increase in 2019 from $3.5 \%$ estimated in 2018 (Donga et al., 2018). Mobile Economy generated 110 billion US dollars which increased Africa's GDP in 2017, and it is expected to generate about $\$ 150$ billion by 2022 with an additional $9 \%$ increment in GDP. This sector further supported 3 million jobs in 2017 (Nabwiiso, 2019).

Africa is gradually emerging as a mobile region because mobile networks are widespread in Sub-Saharan Africa and surpass any other technology in the region (Kozachenko, 2020). African markets are more of the youth (Radcliffe, 2018), and the smartphones are affordable, which leads to increases in mobile subscription penetration. This means Sub-Saharan Africa is the fastest-growing mobile market in the world. In 2016, for instance, there were 420 million unique mobile subscribers and 498 million smartphone users, and in 2020, it is expected that this number will increase to 535 million (Kozachenko, 2020). These have enhanced the growth in data connectivity and have opened new possibilities in digital media and the Internet. (Kozachenko, 2020).

However, despite the Africa population being one-sixth of the world's population, the use of mobile marketing technology applications are low compared to other emerging countries (Kozachenko, 2020). Kozachenko (2020) stressed that the rate at which mobile marketing technology is growing is $7 \%$ of the world's online users (167 million internet users) only. Only $4 \%$ of internet users in Africa adopted the applications while $96 \%$ browse via the web because of its cost factor and the technical features of the majority of the phones used compared to the US, where $91 \%$ of the users use the app, and $9 \%$ are web users. In Africa, South Africa is the leader in mobile application downloads, followed by Ghana and Nigeria (Kozachenko, 2020). Although the $4 \mathrm{G}$ networks launched in the first half of 2018 (which account for about 120 such networks in Africa) and inexpensive smartphones are helping to drive the transition to mobile broadband (Radcliffe, 2018; Nabwiiso, 2019), about 40 per cent of Africa's population is under the age of 16. This population has a significantly lower level of mobile ownership compared to the entire population (Radcliffe, 2018). While the high cost of data makes users even less tolerant of pop-up adverts, auto-play videos and excessive retargeting using mobile phones, Video is considered expensive and buying a handset with little above $450 \mathrm{MB}$ of data costs nearly 10 per cent of monthly income (Radcliffe, 2018; Kozachenko, 2020). These trends are the basis for a high drop-off rate and more subscriptions to ad-blockers (Kozachenko, 2020). Hence, Africa should focus on investing more in mobile markets to leverage opportunities such as markets offer (Donga et al., 2018).

Theoretical underpinning. According to Parker and Castlemen (2009), the commonly used theories to study the influence of technology adoption on small businesses are Theory of Reasoned Action (TRA) (Fishbein and Ajzen, 1975), Technology Acceptance Model (TAM) (Davis, 1989), Theory of Planned Behaviour, (TPB) (Ajzen, 1985), Porter's resource base view models (Porter, 1985) and Rogers's Diffusion of Innovation Theory (IDT) (Rogers, 1983; Rogers, 1995). Although these theories have played a major part in advancing research in the area of systems research, the TRA, TAM, TPB Porter's models, Innovation Diffusion Theory (IDT) are not without their criticisms. For example, TRA focuses on behaviour rather than actions that lead to such behaviours (Fishbein and Ajzen, 1975). It also deals with the performance of a single action or behaviour (Benbasat and Barki, 2007; Eze et al., 2013) while TRA failed to recognise that there is a tendency to choose among alternative behaviour. For example, SMEs family members, friends, and relatives, external parties (Parker and Castleman, 2009), as well as demographic components, shape SMEs executive's decisions. TAM only explains the attitudes and decisions of SME managers on technology adoption (Yu and Tao, 2009) while TPB is matured (Venkatesh et al., 2007), and studies now fine-tune its core constructs and develop alternative variables to predict behaviour. Porter's models, on the other hand, are mostly applied in large firms because their risktaking behaviours to economic goals are high (Eze et al., 2013). This hinders SMEs in obtaining the necessary resources to their benefit (Butler et al., 2007; Beckinsale et al., 2006). Besides, RBT did not sufficiently take into account external forces like customers, suppliers, non-entrepreneurial firms and the demographic components of small business characteristics (Parker and Castleman, 2009). Although DIT differs from the previous theories and explains when and how a new ICT is adopted and rejected (Rogers, 1995), TAM and IDT share similar features. For instance, TAM and IDT have been integrated to investigate the pre-adoption and post-adoption belief, and the results revealed that actual users and potential adopters of IT use different variables that are linked to attitude (Karahanna et al., 1999). However, these models do not focus centrally on the qualities of the demographic characteristics of small business executives.

Although numerous researchers (Chuang et al., 2009; Venkatesh et al., 2007; Chuang et al., 2009; Eze et al., 2014; Eze et al., 2018) have studied factors shaping technology adoption in SMEs, there is still a dearth of research that has applied UET to study SMEs in Ado Ekiti, Ekiti State, Nigeria. This research adopted upper echelon theory (UET) because its primary emphasis is on the qualities of the demographic characteristics (Hambrick and Mason, 1984) of small business managers. According to Hambrick and Mason (1984), the theory stressed that business performance and the choice of a business strategy are shaped by the 


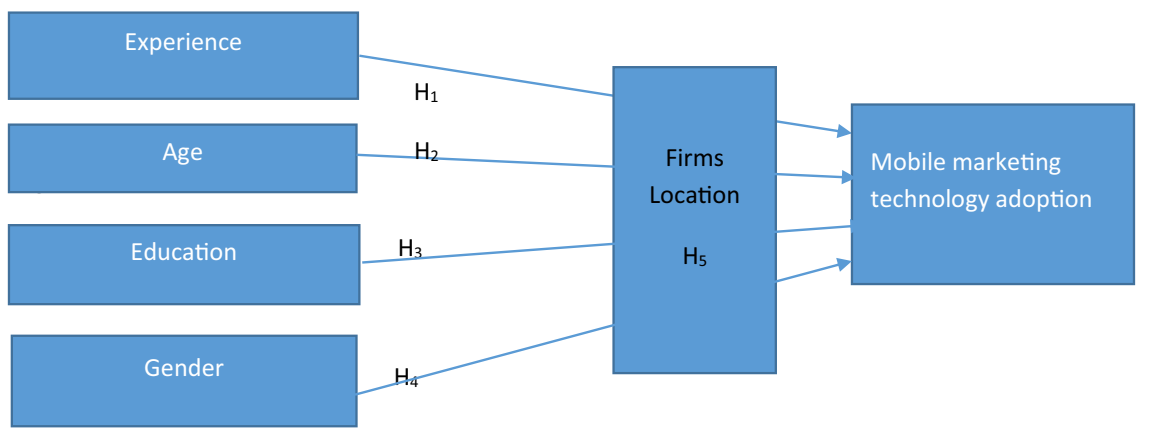

Fig. 1 Analytical framework for the study. This depicts the framework used in investigating the demographic determinants of mobile marketing technology adoption by small and medium enterprises (SMEs) in Ekiti State, Nigeria. The four boxes on the left side show the demographic determinants of mobile marketing technology adoption contexts under which these factors were investigated. They demonstrated the interconnections with three groups of variables. These variables are the independent variables which include experience, age, education, gender, while the dependent variable is the mobile marketing technology adoption. The moderating variable is the firm's location. The initial version of the paper was presented at Proceedings of Informing Science and IT Education Conference (InSITE) 2014.

characteristics of dominant actors within a firm, mainly the top executives. Although the model depicts the main characteristics such as functional track, education, gender, financial position, career experience, age substantially influence SMEs managers' decision on IT adoption behaviour, these characteristics may be shaped by both internal and external forces.

From the external point of view, family members, for example, who are key advisers to the business can shape the overall activities of the business (Simpson and Docherty, 2004). SME managers' characteristics can also be shaped by external sources such as IT experts and vendors and consultants (Eze et al., 2014; Martin and Matlay, 2003; Beckinsale et al., 2006). SMEs executives' decision to acquire new IT can also be influenced by the customers and suppliers (Awa et al., 2015). More so, the intention of ownermanagers to introduce new technology may be determined by the readiness of the consumers which in turn is determined by the level of penetration of the internet within a country, as well as the appreciation of consumers about the technology. The willingness of the consumer to use internet technology and carryout online business transactions in Nigeria is further held up by security issues and high illiteracy rates. The unsteady, unpredictable and competitive nature of the market, lack of financial resources, and increased competitive pressure can shape SMEs' desire to try new technology (Porter and Millar, 1985; Xu et al., 2007). Although UET suggests that both external and internal factors may have a significant impact on those that decide to adopt technology in SMEs, and a decision made may be an important determinant of growth and performance (Galloway and Mochrie, 2005; Martin and Matlay, 2003). This study focuses mainly on the characteristics of top SME executives because these factors were more predominant during the initial analysis and evaluation of the literature. These characteristics include experience, age, education and gender.

Analytical framework and hypotheses. The attitudes towards SMEs' executives on mobile marketing technology adoption are often shaped by such demographic factors as age, experience, gender and education. Although a number of these predictor variables are well investigated, unsophisticated and somewhat superficial in the context of mobile marketing technology, presenting geographical location as a moderator variable offers a potentially unique twist since ICT investigations rarely use location to explain the critical link between ICT adoption and the demographic composition of top management. While businesses consider some geographical areas as having more favourable location because of the resources available in that area and excellent service delivery, others are favourable because employees within that locality are better educated, knowledgeable and more experienced in dealing with issues of mobile marketing technology adoption because of how long they have stayed in those areas. Hence, the framework in Fig. 1 below revealed the interconnections with three groups of variables. These variables are the independent variables which include experience, age, education, gender, while the dependent variable is the mobile marketing technology adoption. The moderating variable is the firm's location and drawing from the empirical review to back the support of the study.

Experience. Experience has been rated as a significant factor that shapes technology adoption (Mud, 1979; Ho and Lim, 2018). Experience shapes cost arrangement, productivity, and employee confidence. This is because the experience is often referred to as an organisational asset. The inexperience of top management executives and inadequate knowledge about IT capabilities discourage adoption (Crook, 2008; Tan et al., 2009; Huang and Rust, 2018). When a manager has a positive experience in terms of how stress-free the innovation is, its perceived usefulness shapes adoption of similar innovations based on stimulus generalisation, technology cluster and, cognitive consistency (see Kotler and Keller, 2009; Kannabiran and Dharmalingam, 2012; Galloway and Mochrie, 2005; Kannan and Li, 2017). Therefore, the knowhow, expertise and the use of mobile devices by top management successfully shape adoption determinants (Ho and Lim 2018; Kübler et al., 2018). Hashim (2007) investigated the association between top management executive experience and technology adoption in SMEs. He established that when the experience is strengthened with IT, SMEs develop and understand the true potential of IT to advance business undertakings.

Similarly, there is a relationship between top management experiences and when (early or late) adoption takes place. Also, where and how experience is acquired matters a lot. A newly employed top management executive rather than the one promoted is more prone to innovativeness and operational modifications to ensure a high level of productivity and growth (Sabherwal et al. 2006). A newly employed top management executive would often impress the organisation by showing a wealth of knowledge and introducing strategies that may trigger the adoption and implementation of mobile marketing technology compared to those within the organisation. This may improve the technological competencies of the firm via reorganisation of tasks.

Therefore, H1: There is a significant relationship between the experience of the top executives' and mobile marketing technology adoption.

Age. There are several scholarly works (Sabherwal et al., 2006; Hedges, 2010; Lamberton and Stephen, 2016) that have found the 
relationships between the age, top executives and the features of the organisation. Li et al. (2017) stressed that age has an impact on perceived usefulness and the performance of an employee on an IT base assignment (Venkatesh and Morris, 2000). Younger Executives are more open to taking risks (Glover, 2010; Shiau et al., 2009; Li et al., 2017). Hedges (2010) found that top management executives below the age of 39 are more open to adopting mobile marketing technology and more than 70 per cent of these executives use mobile devices as an essential communication tool compared to 28 per cent of the executives who are between 50 and 60 years old. This implies that young executives are much more digitally engaged (Glovers, 2010; Melumad et al.,2019). This has the potential to improve business operations since such devices can be used to perform various tasks (Ransbotham et al., 2019). Similarly, Li et al. (2017) argued that age might be the reason why small businesses are more innovative. Arguably, the tendency that younger executive is more likely to engage with mobile marketing technology compared to older executives is because they are more open to new experiences (Chuang et al., 2009). While top management executives who are older do have physical, social, and mental strengths (Awa et al., 2015) to hold on, and maybe innovative and committed (Hedges, 2010), younger executives are usually more open to innovations and change(Spry Foundation, 2005; Ransbotham et al., 2019; Li et al., 2017).

Therefore, H2: There is a significant relationship between the ages of top executives and the rate at which mobile marketing technology is adopted.

Education. The extent of formal education of top management team, as well as their competencies, significantly shape technology adoption (Shiau et al., 2009; Federici, 2009; Sabherwal et al., 2006; Wang et al., 2019) and aid rapid changes in technology. To some extent, the level of educational attainment influence top executives' belief and value systems, norms, skills, preferences, ability to study, and state-of-the-art inventions (Federici, 2009). Rogers (1995) stressed that top management executives who are innovative are more aggressive in inventing something new because of their experience, skills and knowledge acquired over time to revive the organisation in periods of economic meltdown profitably. Executives who are highly educated are diverse, exposed and knowledgeable about value creation, encourage initiatives, and are prepared to source the right information from the right experts that will steer the affairs of the organisation. These sets of executives are open to acquiring new things, especially innovations, and they ensure that everyone in the organisation runs with innovations. This is different from top management executives who did not acquire a considerable level of education which usually display significant levels of risk of antipathy because they feel that those that are well educated might introduce something new that will lead to change. They only see the need to change when the initial plan fails.

Hence, H3: There is a significant relationship between the SME top executives level of education and mobile marketing technology adoption.

Gender. Not only does the gender of top management executives shape an organisation strategic directions and risk-taking behaviours. It also influences management decisions and individual behaviour (Kannabiran and Dharmalingam, 2012; Xu et al., 2017). According to Hofstede, (1991), gender is core to determining human behaviour and the decision-making process of SMEs Executives. Gender plays a significant role in shaping how small business managers respond to and use technology. For instance, Jimmie and Mukhopadhyay (2010) examined the relationship between gender and IT adoption and found that men have more computers at home compared to women Also, Geffen and Straub, (1997) adopted the technology Acceptance Model (TAM) to investigate the differences in the use of E-mail, by males and females. The result shows that men are more comfortable in the use of technology compared to women. In the same vein, Lu et al. (2003) note that in technology-derived market, young male executives are most times early adopters compared to females who are less inclined and motivated to adopt and use technology (Gefen and Straub, 1997; Xu et al. (2017). Although previous research works (Ransbotham et al., 2019; Li et al., 2017; Gefen and Straub, 1997; Olatokun, 2007) have stressed that there is a wide margin between males and females in deploying digital platforms, recent research has shown that women embracing the technology (Olatokun, 2007). However, the status of women in Nigeria contributes to the low usage of technology. In Nigeria, for instance, women account for 30 per cent of professional posts, 17 per cent of managerial positions, and 30 per cent of clerical positions while 17 per cent are employed in other categories. They are often seen occupied with low-paying jobs, mainly in the informal sector (Olatokun, 2007).

Thus, H4: There is a significant relationship between the genders of SME top executive and mobile marketing technology adoption

The moderator. The adoption of emerging mobile marketing devices shapes a firm's relationships with the outside world. The physical location of the business may moderate this. A customer's choice of a business could be as a result of the volume, different product varieties and the cost associated with accessing the business. It has been argued that scholars use location as a geographic factor to develop frameworks aimed at positioning and analysing the nature, structure, complexity associated with firms in different geographic parts. Distance and size is no longer a barrier. Despite the emergence of mobile marketing devices and many SMEs in rural areas using technology as a strategic tool to improve physical nearness to overcome the challenges of communication caused by distance, small businesses still adopt these solutions slowly Somuyiwa and Adewoye, 2010; Ransbotham et al., 2019).

The degree to which a business adopts and utilises mobile devices within a particular area is connected with the resources located in that area. While businesses consider some geographical areas as having more favourable location because of the resource available in that area, excellent service delivery, others are favourable because employees within that locality are better educated, knowledgeable and experienced because of how long they have lived in those areas. Therefore, nearness to industrial undertakings encourages a network of external experts who are experienced and knowledgeable within a geographical location (Wever and Stam, 1999; Saxenian, 1994; Ho and Lim, 2018). There is a positive association between mobile marketing technology adoption and population density and this relationship continues to grow as the complexity of mobile technology devices increases.

Therefore, H5: the relationship between demographic elements and mobile marketing technology adoption is moderated by the location of small businesses

\section{Methods and research design}

This study adopted a quantitative approach. The survey approach was used to collect data from 230 SMEs drawn randomly from 630 small businesses in Ado Ekiti, Ijero and Ikole town, all in Ekiti State, Nigeria. These towns were considered the most populated towns in Ekiti state in the last census (https://www. citypopulation.de/php/nigeria-admin.php?adm1id=NGA013).

Thus, they are referred to as the most commercially viable areas by the National Bureau of Statistics in Nigeria. These SMEs have registered their businesses with the Corporate Affairs Commission (CAC) of Nigeria. CAC is responsible for the registration of 
Table 1 Classes of SMEs and sample description.

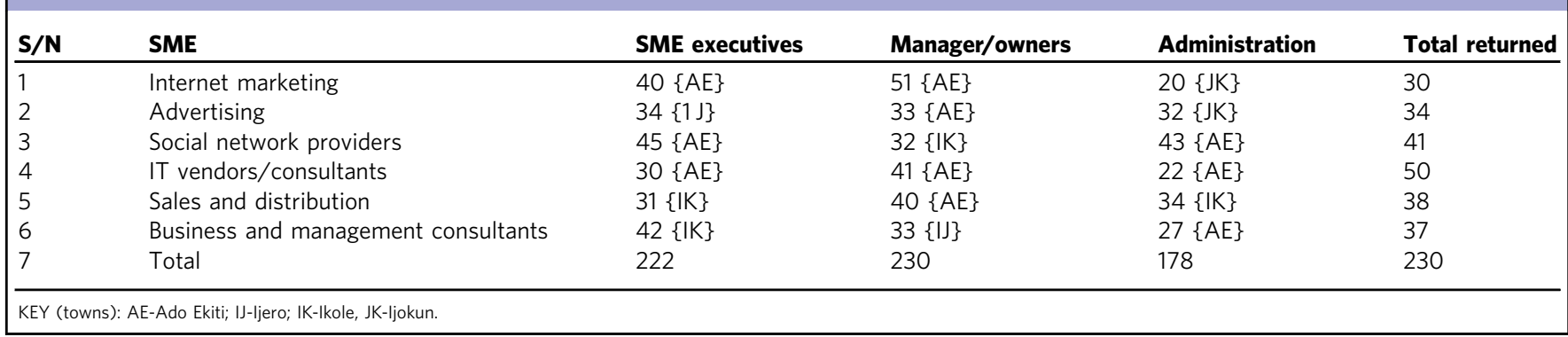

businesses in Nigeria. The information associated with the population of the study was guided by records gotten from the CAC. It is important to note that positivist ontology was employed because the epistemology underlying the assumption of the quantitative paradigm and descriptive approach is to produce reality by polarity. Drawing on Krejcie and Morgan's (1970) work, questionnaires were designed which were distributed to SMEs owners or their managers who are service-oriented and render services such as internet marketing and advertising, social network provider, IT vendor/consultancy, sales and distribution, business and management consultancy. The modes of reaching this business include both online and offline. Before the questionnaire was distributed a letter was sent to SMEs via their emails and by post using the addresses (physical and emails) obtained from the Corporate Affairs Commission (CAC) addressing confidentiality issues, requesting for their consent, and to take part in filling the questionnaires. It is important to note that SMEs were selected because: (i) they have at least 35 workers (ii) they must be owners of the business (iii) they must directly be involved in the management and decision making of the business. Table 1 shows different SME classes, towns and cities where the samples were drawn, and the number of SMEs sampled in each town.

Operational measures of instruments. Mobile marketing technology adoption measures the degree of use of mobile marketing devices to aid the decision-making process, operations, organisation and management (Thong (1999). Mobile marketing technology adoption measures the degree of interconnectivity between small businesses and their trading partners, customers, and suppliers and the contributions of such relationships to inventory management, costs and customer service. Managers who are also owners were asked to rate the extent to which their businesses adopt mobile marketing technology on a seven-point scale Series of statements were established based on the hypotheses above to reveal the definitions associated with the variables, review of extant literature and the objectives of the study. The researchers measured experience in terms of career stability. Age is in years and is defined as an adult who is 40 and above years. Education is defined as the academic attainment which constitutes First School Leaving Certificate, (2) WASC/GCE, (2) Diploma (ND/HND) (3) B.Sc., (4) Post-graduates, and (5) experts without formal education. Gender is represented by 1 for male and 0 for female). Also, the location was parameterised using 4 levels of hierarchical multiple regression to assess the interaction of the variables.

Validity and reliability. Several empirical evidence (Lu et al., 2003; Sabherwal et al., 2006; Shiau et al., 2009) have highlighted the significance of validity and these studies have also confirmed the validity of study variables. In line with these studies, the instruments used in this research were subjected to the enquiry of informed persons (face validity) in a bid to ensure that the

\begin{tabular}{|llll|}
\hline \multicolumn{2}{|l|}{ Table 2 Descriptive statistics. } & & \\
Variable & Mean & N & SD \\
\hline Experience & 4.87 & 230 & 1.387 \\
Age & 5.02 & 230 & 1.427 \\
Education & 4.78 & 230 & 1.216 \\
Gender & 3.99 & 230 & 1.512 \\
\hline
\end{tabular}

sentences constructed sufficiently represent the items measured. Before the questionnaires were distributed to the respondents, the researchers also conducted a pilot survey to initially test the scales on small sampling units so that inconsistencies can be resolved before the primary survey is carried out. The investigators adopted Cronbach Alpha ( $\alpha$ ) as the reliability instrument. The reliability was measured, and the result showed 0.84 , which surpassed Nunnally's (1978) benchmark of 0.7. This implies that the instrument was relevant to the subject under investigation.

\section{Results and discussion}

The researcher adopted SPSS (version 18) to analysis the data. Date linked with the variables; experience, age, education, gender were used, as well as the moderating effects such as the firm's location were used. The reason being that mobile marketing technology adoption is associated with numerous personal factors. A four-step ranked regression technique was adopted to test the hypotheses. These four-step regression techniques include (1) factor-loading of the variables under control, (2) loading of mobile marketing technology adoption, (3) the moderator (4) the relations between mobile marketing technology adoption and the associated moderator

Table 2 above depicts the means and standard deviations of the controlled variables. The mean scores associated with the variables are between 3.99 to 5.02 . These scores imply that participants are confident that all the variables have comparatively high scores in shaping mobile marketing technology adoption. The researchers used hierarchical multiple regression analysis because it provides tremendous flexibility and helps in assessing the interaction terms (determine whether the effect of one independent variable depends on the value of another variable). Although the coefficients of some of the demographic variables in Table 3 are weak, the table below indicates the summary of the model that revealed predictor variables which describe an overall estimate of $47 \%$ variations of mobile marketing technology adoption behavior (see $R^{2}=0.474, p<0.01$ ). This suggests that the decision-making characteristics of major actors are a function of the demographic factors which unswervingly shape mobile marketing technology adoption in small businesses. These findings are consistent with several previous research works (see Lu et al., 2003). 


\section{Table 3 Regression analysis.}

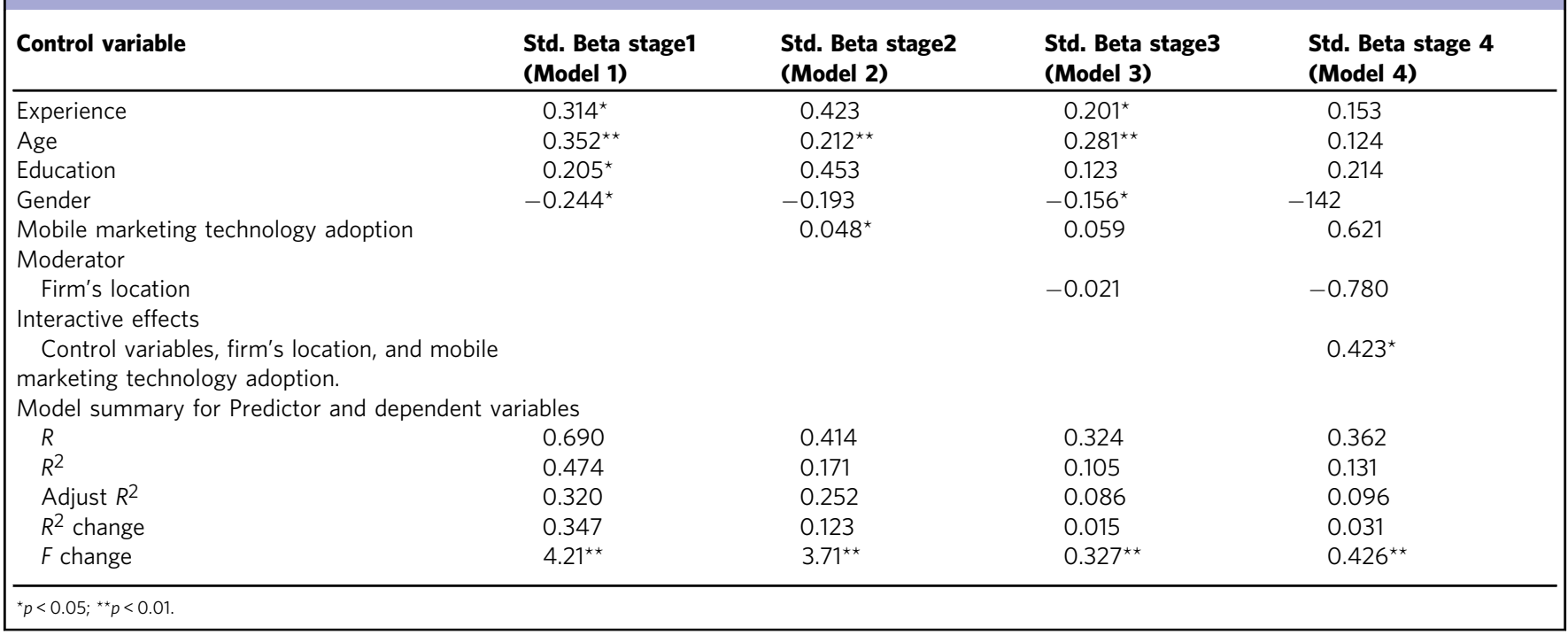

From Table 2 above, when experience was incorporated into the equation, the results showed that there was a positive correlation coefficient $(\beta=0.314, p<0.05)$, hence H1 was accepted. Comparing experience with education, the results indicated that experience is significant in determining mobile marketing technology adoption which is similar to earlier studies (see Iberia et al., 1998; Kannabiran and Dharmalingam, 2012; Hashim, 2007; Chuang et al., 2009; Wainwright et al., 2005; Tan et al., 2009; Melumad et al., 2019). For instance, a study conducted by Choudrie and Dwivedi (2005) on broadband use within households shows that technology adoption among a range of firms is shaped by top executive knowledge of its benefits and the firm's expectations instead of the educational attainment of decision-makers.

Secondly, when age was included in the equation, the analysis shows that it has a significant positive relationship with mobile marketing technology adoption $(\beta=0.352, p<0.01)$, which supported $\mathrm{H} 2$. While the finding agrees with some past research works (Gefen and Straub, 1997 and Hambrick and Mason, 1984), Sabherwal et al. (2006) found that age is significant, but with a negative value. This variation may be because mobile devices cut across different age brackets in the western world, compared to third world countries. The results show that younger people, mainly executives, are regularly engaged with the devices to develop and build a competitive edge.

Thirdly, there was a significant positive correlation coefficient $(\beta=0.205, p<0.05)$, between education and mobile marketing technology adoption. This result supports H3 which supports earlier studies (Choudrie and Dwivedi, 2005; Chaung et al., 2009; Ho and Lim, 2018) while others (Melumad et al., 2019) have different views. Choudrie and Dwivedi (2005) investigated the use of broadband among members of households. They found that IT adoption in some organisations is determined by how knowledgeable the top management of the business is and the expectations of the organisation in terms of the benefits rather than the level of education attended.

Fourth, there was a significant negative correlation coefficient $(\beta=-0.244, p<0.05)$ when gender was incorporated into the equation, which led to the rejection of $\mathrm{H} 4$. Although the results revealed that the sex of the executives influences mobile marketing technology adoption, this is not consistent with other similar research works (Hashim, 2007; Li et al., 2017). Galloway and Mochrie (2005) found that males and females have different motives for using mobile marketing technology devices; for some, it is to increase productivity, while others see these devices as application packages.

Finally, when the location of the firm was incorporated into the equation, there was a significant positive interaction $(\beta=0.423$, $p<0.05)$ which revealed that the firm's location moderates the relationship between mobile marketing technology adoption and the experience, age, education and gender of top executives of SMEs. The result supports H5. Also, there was an incremental variance of $16 \%$ associated with the location of the firm, which doubled to $32 \%$. When all the interactive terms were loaded, the $\mathrm{F}$ change statistics associated with the entire models were significant at $p<0.01$.

\section{Conclusion and implications}

This research investigated the influence of the experience of the decision-makers, age, education and gender on the adoption of mobile marketing technology infrastructures in SMEs. It measured the effects of the above-mentioned four demographic factors. The study discovered that organisations' directions are primarily dependent on the views and expectations of top management executives. From the analysis, the results revealed that the age of the top executives ranked the most statistically significant demographic factor that shaped mobile marketing technology adoption, followed by experience and education, respectively. Gender was associated with a negative correlation coefficient while the location of the organisation moderates the association between mobile marketing technology adoption and the demographic features of the decision-makers. This finding has some implications.

Several theories have been adopted to study factors shaping the adoption of mobile marketing technology adoption by SMEs. However, these theories have not been used to promote the role of demographic idiosyncrasies of top management executives, especially in SMEs. Although a number of predictor variables used in these theories are well investigated, unsophisticated and somewhat superficial in the context of mobile marketing technology, presenting geographical location as a moderator variable offers a potentially unique twist since ICT investigations rarely use location to explain the critical link between ICT adoption and the demographic composition of top management. Hence, this study contributes to the existing literature by taking a step further to bridge the gap in knowledge by investigating the demographic peculiarities of top management executives of SMEs and how these factors significantly explain and predict mobile marketing technology 
adoption using location to explain the critical link between ICT adoption and the demographic structure of top management.

From the managerial point of view, the study proposed that an adequate policy framework should be developed to guide SMEs in developing strategies for competitive advantage by understanding both the individual and group characteristics such as experience, age, and education of those that make decisions in the organisation. Younger executives with mobile marketing experience, knowledge and education should be interacted with in order to meet the everdynamic mobile marketing technology needs. Also, the Nigerian government and its agencies should ensure that facilities and infrastructures are developed and distributed evenly to discourage rural-urban migration. This will inspire SMEs to exploit the full potentials of ICT, regardless of their locations. Finally, service providers are required to raise the switching costs of young executives by improving mobile marketing infrastructures regularly. At the same time, the organisation should develop enabling environment for constant learning and exposure to mobile marketing needs.

Limitations and further research. First, since the sample is drawn from only one geo-political zone in Nigeria (SMEs in the south-west zone), the study cannot be adequately generalised across all the six geo-political zones in Nigeria. Therefore, other studies should adopt the same approach or use a mixed-method approach to investigate four or five zones since no two zones are precisely the same to generalise the finding through external validity and cross-validation fully. Also, the measures adopted in this research are subjective, some errors are likely to occur which are prone to bias, though several steps were introduced to reduce the effect on the results. Finally, while the experience of the decision-makers, age, education and gender were investigated, other demographic variables were not considered in this study. Further studies should also look at factors such as marital status, income and others.

\section{Data availability}

The data is not available for deposit due to confidentiality issues.

Received: 5 March 2020; Accepted: 15 February 2021; Published online: 19 March 2021

\section{References}

Ajzen I (1985) From intentions to actions: A theory of planned behavior In: Kuhl J, Beckmann J (eds) Action control: From cognition tobehaviour. Berlin: Springer

Alba M, Diez L, Olmos E, Rodriguez R (2005) Global Performance Management for SMEs. International Federation for Information Processing Book Series. Springer, Boston

Albaladejo-Pina IP, Díaz-Delfa MT (2009) Tourist preferences for rural house stays: evidence from discrete choice modelling in Spain. Tourism Manag 30(6):805-811

Al-Qirim N (2007) The adoption of E-commerce communications and applications technologies in small businesses in New Zealand. Electronic Commerce Res Appl 6(4):462-473

Apulu I, Latham A, Moreton R (2011) Factors affecting the effective utilization and adoption of sophisticated ICT solution: case studies of SMEs in Lagos, Nigeria. J Syst Inform Technol 13(2):125-143

Awa HO, Asiegbu IF, Igwe SI, Eze SC (2011) Collaborative Experience of Value Chain Architecture: A Systemic Paradigm To Building Customer Loyalty. Global J Manag Bus 11(3):69-80

Awa H, Nwibere B, Inyang B (2010) The uptakes of electronic commerce by SMEs: a meta theoretical framework expanding the determining constructs of TAM and TOE framework. J Global Business Technol 6(1):1-27

Awa HO, Baridam DM, Nwibere BM (2015) Demographic determinants of electronic commerce (EC) adoption by SMEs. J Enterpr Inform Manag 28(3):326-345

Balasubramanian S, Peterson RA, Jarvenpaa SL (2002) Exploring the implications of m-commerce for markets and marketing. J Acad Market Sci 30(4):348-361

Beckinsale M, Levy M, Powell P (2006) Exploring Internt adoption drivers in SMEs Electron Mark 16(4):361-370

Benbasat I, Barki H (2007) Quo vadis, TAM? J Assoc Inf Syst 8(4):211-218
Brown D, Lockett N (2004) Potential of critical E-applications for engaging SMEs in E-business: a provider perspective. Eur J Inform Syst 13(1):21-34

Butler A, Reed M, Grice PL (2007) Vocational training: Trust, talk, and knowledge transfer in small businesses. J Small Bus Enter Dev 14(2):280-293

Caldeira M, Ward J (2002) Understanding the successful adoption and use of IT/IS in SMEs: an explanation from Portuguese manufacturing industries. Informat Syst J 12(2):121-152

Castelo N, Thalmann N (2019) Robot or human? Consumer Perceptions of Human-Like Robots. Working Paper

Ciechanowski L, Przegalinska A, Magnuski M, Gloor P (2019) In the shades of the Uncanny Valley: an experimental study of human-Chatbot interaction. Future Generation Computer Syst 92:539-548

Charoensukmongkol P, Sasatanun P (2017) Social media use for CRM and business performance satisfaction: the moderating roles of social skills and social media sales intensity. Asia Pacific Manag Rev 22(1):25-34

Choudrie J, Dwivedi Y (2005) The demographics of broadband residential consumers in local British community: the London Borough of Hillingdon. J Computer Inform Syst 45(4):93-101

Chuang T, Nakatani K, Zhou D (2009) An exploratory study of the extent of information technology adoption in SMEs: an application of Upper Echelon theory. J Enterpr Inform Manag 22(1/2):183-196

Crook N (2008) Enterprise 2.0: how social software will change future of work Gower Publishing Ltd, Farnham

Davis FD (1989) Perceived usefulness, perceived ease of use and acceptance of information technology. MIS Quarterly 3(3):319-340

De Haan E, Kannan PK, Verhoef PC, Wiesel T (2018) Device switching in online purchasing: Examining the strategic contingencies. J Market 82(5):1-19

Donga G, Kadyamatimba A, Zindiye S, Chibonda T (2018) Consumer acceptance of mobile marketing through mobile phones: A case study of South African University students. Inf Technol J 7(1):1-10

Dubé JP, Fang Z, Fong N, Luo X (2017) Competitive price targeting smartphone coupons. Market Sci 36(6):944-975

Economides N, Jeziorski P (2017) Mobile Money in Tanzania. Market Sci 36 (6):815-837

Eze SC, Awa H, Okoye J, Emecheta B, Anazodo R (2013) Determinant factors of information communication technology (ICT) adoption by governmentowned universities in Nigeria. J Enterp Inf Manag 26(4):427-443

Eze S, Duan Y, Chin H (2014) Examining Emerging ICT's Adoption in SMEs from a dynamic Process Approach. Inform Technol People 27(1):63-82

Eze SC, Chinedu-Eze CV (2018) Examining information and communication technology (ICT) adoption in SMEs: a dynamic capabilities approach. J Enterprise Inform Manag 31(2):338-356

Eze S, Chinedu-Eze V, Bello A, Inegbedion H, Nwanji T, Asamu F (2019a) Mobile marketing technology adoption in service SMEs: a multi-perspective framework. J Sci Technol Policy Manag 10(3):569-596

Eze S, Olatunji S, Chinedu-Eze V, Bello A, Ayeni A, Peter F (2019b) Determinants of perceived information need for emerging ICT adoption: A study of UK small service businesses. Bottom Line 32(2):158-183

Eze S, Chinedu-Eze V, Bello A (2019c) Determinants of the dynamic process of emerging ICT adoption in SMEs-actor-network theory perspective. J Sci Technol Policy Manag 10(1):2-34

Eze, SC, Chinedu-Eze, VC (2019) Critical factors influencing mobile marketing technology adoption by micro-businesses in Nigeria: A preliminary study, 16th International Joint Conference on e-Business and Telecommunications Prague the Czech Republic Jul 26, 2019-Jul 28, 2019

Eze SC, Chinedu-Eze VCA, Okike CK, Bello AO (2020) Critical factors influencing the adoption of digital marketing devices by service-oriented microbusinesses in Nigeria: a thematic analysis approach. Humanit Soc Sci Commun 7(90):1-14

Eze SC, Olatunji S, Chinedu-Eze VC, Bello AO (2018) Key success factors influencing SME managers' information behaviour on emerging ICT (EICT) adoption decision-making in UK SMEs. The Bottom Line 31(3\4):250-275

Federici T (2009) Factors Influencing ERP Outcomes in SMEs: a post-introduction assessment. J Enterpr Inform Manag 22(1/2):81-98

Fong NM, Fang Z, Luo X (2015) Geo-Conquesting: competitive locational targeting of Mobile promotions. J Market Res 52(5):726-735

Fishbein M, Ajzen I (1975) Belief, attitude, intention and behavior: An introduction to theory and research. Reading, MA: Addison-Wesley

Galloway L, Mochrie R (2005) The use ICT in rural firms: a policy-oriented literature review. Info 7(3):33-46

Gamage A (2003) Small and medium enterprise development in Sri Lanka: a review. http://wwwbiz.meijo-u.ac.jp/SEBM/ronso/no34/aruna.pdf

Gefen D, Straub D (1997) Gender difference in the perception and use of E-mail: an extension to the technology acceptance model. MIS Quart 21(4):389-400

Ghose A, Kwon HE, Lee D, Oh W (2019) Seizing the commuting moment: contextua targeting based on mobile transportation apps. Inform Syst Res 30(1):154-174

Gill M, Sridhar S, Grewal R (2017) Return on engagement initiatives: a study of a business-to-business Mobile app. J Market 81(4):45-66 
Glover M (2010) Reaching Executives through mobile adv. Forbes/INSIGHTS. pp. $12-13$

Grewal L, Stephen AT (2019) In Mobile, we trust the effects of mobile versus no mobile reviews on consumer purchase intentions. J Market Res 002224371983451.

Grewal D, Roggeveen AL, Nordfält J (2017) The future of retailing. J Retail 93(1):1-6 Grewal D, Ahlbom CP, Beitelspacher L, Noble SM, Nordfält J (2018) In-store Mobile phone use and customer shopping behaviour: Evidence from the field. J Market 82(4):102-126

GSMA (2018) Spotlight on Nigeria: Delivering a digital future. https://www.gsma. com/publicpolicy/wp-content/uploads/2019/02/GSMA-Spotlight-on-NigeriaReport.pdf

Hadidan W (2020) An Investigation of the Influence of Social CRM on Brand Reputation and Brand Loyalty In Developing Country: Evidence from the Nigerian Telecoms Industry, a dissertation submitted to University of Salford. https://usir.salford.ac.uk/id/eprint/56224/2/wagdi\%20final\%20Thesis\% 202020.pdf (Accessed 2/2/21)

Hambrick D, Mason P (1984) Upper Echelons: the organization as a reflection of its top managers. Acad Manag Rev 9(2):193-205

Hashim J (2007) Information Communication Technology (ICT) Adoption among SMEs owners in Malaysia. Int J Business Inform 2:221-240

Hedges M (2010), the need to be nimble. Forbes/INSIGHTS. pp. 6-8

Ho SY, Lim KH (2018) Nudging moods to induce unplanned purchases in imperfect Mobile personalisation contexts. MIS Quart 42(3):757-778

Hofstede G (1991) Culture and organization. McGraw-Hill, New York

Huang MH, Rust RT (2018) Artificial intelligence in service. J Service Res 21 (2):109467051775245

Iberia M, Zinatelli N, Cavage A (1998) Analysis of information technology success in small firms in New Zealand. Int J Inform Manag 18(2):103-119

Investopedia (2018) Mobile Advertising Definition. Investopedia website. https:// www.investopedia.com/terms/m/mobile-advertising.asp. 22 June 2018

Jimme J, Mukhopadhyay S (2010) A Bi-national examination of gender and IT Adoption. International Journal of Society Systems Science 2(3):255-268

Kannan PK, Li HA (2017) Digital marketing: a framework, review and research agenda. Int J Res Market 34(1):22-45

Kannabiran G, Dharmalingam P (2012) Enablers and inhibitors of advanced information technologies adoption by SMEs: an empirical study of auto ancillaries in India”. J Enterpr Inform Manag 25(2):186-209

Karahanna E, Straub DW, Chervany NL (1999) Information technology adoption across time :a cross-sectional comparison of pre-adoption and post-adoption beliefs. MIS Quarterly 23(2):183-213

Kotler P, Keller K (2009) Marketing management. 13th edn. Pearson Prentice Hall, Upper Saddle River, New Jersey

Kozachenko K (2020) Sub-Saharan African mobile market: rule of the mobile money. https://applift.com/blog/app-market-sub-saharan-africa,aCCCESSED 15th May 2020

Krejcie and Morgan (1970) Research Methods for Business. In: Sekaran U (2003) John Wiley \& Sons, New York

Kübler R, Pauwels K, Yildirim G, Fandrich T (2018) App popularity: where in the world are consumers most sensitive to Price and user ratings? J Market 82 (5):20-44

Lamberton C, Stephen AT (2016) A thematic exploration of digital, social media, and mobile Marketing: research evolution from 2000 to 2015 and an agenda for future inquiry. J Market 80(6):146-172

Li C, Luo X, Zhang C, Wang X (2017) Sunny, rainy, and cloudy with a chance of Mobile promotion effectiveness. Market Sci 36(5):762-779

Lucchetti R, Sterlacchini A (2001) Factors affecting the adoption of ICTs among SMEs: evidence from an Italian Survey. Vol. 155 Quaderni Di Ricerca

Ma J, Suntornpithug N, Karaatli G (2009) Mobile advertising? Does it work for everyone? Int J Mobile Market 4(2):28-35

MacGregor R, Vrazalic I (2005) A basic model of electronic commerce adoption barriers: a study of regional small businesses in Sweden and Australia. J Small Business Enterpr Dev 12(4):510-527

Martin L, Matlay H (2001) Blanket approaches to promoting ICT in small firms: Some lessions from the IDT ladder adoption model in the UK. Internet Res: Elect Networking Appl Pol 11(5):399-410

Mehrtens J, Cragg P, Mills A (2001) A model of internet adoption by SMEs. Inform Manag 39:165-176

Melumad S, Inman JJ, Pham M (2019) Selectively emotional: how smartphone use changes user-generated content. J Market Res 56(2):259-275

Mutuala S, Brakel P (2006) E-readiness of SMEs in the ICT Sector in Botswana concerning Information Access. Electronic Libr 24(3):402-427

Nabwiiso S (2019) Africa next big mobile market, a new report reveals. https:// www.busiweek.com/africa-next-big-mobile-market-a-new-report-reveals/ Accessed 14 May 2020

Nunnally J (1978) Psychometric theory. McGraw-Hill, New York

OECD (2000a) Local access pricing and e-commerce: an update on the statistics. Organization for Economic Co-operation and Development, Paris
OCED (2000b) Development Co-operation-2000 Report. https://www.oecd.org/ newsroom/developmentco-operation-2000report.htm (Accessed 2/2/21)

Olatokun WM (2007) Availability, accessibility and use of ICTS by Nigerian women academics. Malaysian J Libr Inform Sci12(2):13-33

Ongori H, Migrio S (2010) Information and communication technology adoption: a literature review. J Chinese Entrepreneurship 2:93-104

Ojeme S, Onuba I (2010) CBN sets up N200bn SME Credit Guarantee Scheme The Punch. Vol. 17 Monday, April 19

Lu J, Yu C, Yao J (2003) TAM for wireless internet. Internet Res 13(3):206-222

Parker CM, Castleman T (2009) Smallfirm e-business adoption: a critical analysis of theory. J Enterp Inf Manag 22(1/2):167-182

Park J, SuJin Y (2006) The moderating role of consumer trust and experiences: Value-driven usage of mobile technology. Int J Mobile Market 1(2):24-32

Porter ME (1985) Competitive advantage: Techniques for analysing industries and competitors New York: The Free Press

Porter M, Millar V (1985) How information gives you competitive advantage? Harv Bus Rev 63(4):149-160

Radcliffe D (2018) Mobile in Sub-Saharan Africa: Can the world's fastestgrowing mobile region keep it up? https://www.zdnet.com/article/mobilein-sub-saharan-africa-can-worlds-fastest-growing-mobile-region-keep-itup/ 15 April 2020

Ransbotham S, Lurie NH, Liu H (2019) Creation and consumption of Mobile word of mouth: how are Mobile reviews different? Market Sci 38:773-792

Raymond L, Bergeron F (2008) Enabling the Business Strategy of SMEs through Ebusiness capabilities: a strategic alignment. Perspect Industrial Manag Data Syst 108(5):577-595

Rogers E (1983) Diffusion of innovation New. New York: Free Press

Rogers E (1995) Diffusion of innovations. 4th edn. The Free Press, New York

Sabherwal R, Jeyaraji A, Chowa C (2006) Information systems success: individual and organizational determinants. Manag Sci 52(12):849-864

Saxenian A (1994) Regional advantage. Harvard University Press, Cambridge

Scupola A (2009) SMEs' E-commerce adoption: perspectives from Denmark and Australia". J Enterpr Inform Manag 22(1/2):152-166

Shiau W, Hsu P, Wang J (2009) Development of measures to assess the ERP adoption of small and medium enterprises. J Enterpr Inform Manag 22(1/2):99-118

Shareef MA, Dwivedi YK, Kumer Vinod V, Kumar U (2017) Content design of advertising for consumer exposure: Mobile Marketing Through short messaging services. Int J Inform Manag 37:257-268

Shankar V, Venkatesh A, Hofacker C, Naik P (2010) Mobile marketing in the retailing environment: current insight and future research avenue. J Interactive Market 24:111-120

Simpson M, Docherty A (2004) E-commerce adoption support and advice for UK SMEs. J Small Business Enterpr Dev11(3):315-328

Somuyiwa A, Adewoye J (2010) Managing logistics information systems: theoretical underpinning. Asian J Business Manag 2:41-47

Spry Foundation (2005) Older Adults and the World Wide Web. www.Spry.org.

Swanepoel H (2015) Full adoption of mobile marketing in Africa. Trends 2015. https:// www.bizcommunity.com/Article/196/687/122736.html, Accessed 15, May 2020

Tan K, Chong S, Eze U (2009) Internet-based ICT adoption: Evidence from Malaysia SMEs,". Industr Manag Data Syst 109:224-244

Thong J (1999) An integrated model of information systems adoption in small businesses. J Manag Inform Syst 15(4):27-31

Tong S, Luo X, Xu B (2020) Personalized mobile marketing strategies. J Acad Market Sci 48:64-78

Tornatzky L, Fleischer M (1990) The process of technology innovation. Lexington Books, Lexington

Uzor B (2013) Low-income group seen as drivers of sustainable e-commerce growth in Nigeria. Business Day. 6-8 Sep 2013, p. 4

Venkatesh V, Davis F, Morris MG (2007) Dead or alive? The development trajectory and future adoption research. J Assoc Info Syst 8(4):267-286

Venkatesh V, Morris M (2000) Why don't men ever stop to ask for direction? Gender, social influence and their role in technology acceptance and usage behaviour. MIS Quart 24(1):115-139

Wang F, Zuo L, Yang Z, Wu Y (2019) Mobile searching versus online searching: differential effects of paid search keywords on direct and indirect sales. J Acad Market Sci 47:1151-1165

Wainwright D, Green G, Mitchell E, Yarrow D (2005) Toward a framework for benchmarking ICT practice, competence, and performance in small firms. Int J Libr Inform Services 6:39-52

Wever E, Stam E (1999) Clusters of high technology SMEs: the Dutch case. Region Stud 33(4):391-400

Windrum P, Berranger P (2002) The Adoption of E-business Technology by SMEs." www.merit.unimaas.nl/publications/rmpdf/2002/rm2002-023.pdf

Yesbank (2009) Technology for financial efficiency. YES BANK's Knowledge Banking Publication. 1(1)

Xu K, Chan J, Ghose A, Han SP (2017) Battle of the channels: the impact of tablets on digital commerce. Manag Sci63(5):1469-1492 
Mud R (1979) Individual differences and MIS success: a review of the empirical literature. Manag Sci 25(10):966-979

Yu C, Tao Y (2009) Understanding business level innovation technology adoption. Technovation 29(2):92-109

\section{Author contributions}

All the authors greatly contributed to designing, analysing and interpretation. They were also involved in drafting and revising the paper. Collectively, they agreed on the final version to be published and accountable for all the aspects of the work.

\section{Competing interests}

The authors declare no competing interests.

\section{Additional information}

Correspondence and requests for materials should be addressed to S.C.E.

Reprints and permission information is available at http://www.nature.com/reprints
Publisher's note Springer Nature remains neutral with regard to jurisdictional claims in published maps and institutional affiliations.

(c) The Author(s) 2021 